Johannesburg, South Africa

bb.aisha@gmail.com

Cite this as: BMJ2021;373:n747

http://dx.doi.org/10.1136/bmj.n747

Published: 1 April 2021

\section{Covid-19: Ivermectin's politicisation is a warning sign for doctors}

\author{
The drug ivermectin has divided the medical community in South Africa and elsewhere, with some \\ arguing it can both prevent and treat covid-19. Bibi-Aisha Wadvalla explains how the case \\ encapsulates the central argument: do doctors or scientists know best?
}

\section{Bibi-Aisha Wadvalla freelance journalist}

As vaccination rollouts begin, the covid-19 pandemic continues. Doctors, particularly in low and middle income countries, are desperate to find effective treatments. Yet despite the high number of studies that have been undertaken, few have delivered clear cut results.

In the mix is ivermectin, a cheap antiparasitic drug widely used for nearly 50 years in animals and humans against diseases like lymphatic filariasis and onchocerciasis. ${ }^{1}$ During the pandemic, some doctors have claimed it to be effective for both prophylaxis and treatment of covid-19.

The debate has reached fever pitch in South Africa, which has the worst infection rate in Africa. Groups of doctors and patients have pressured the government into granting emergency approval for treatment of covid-19, enabling wider access to a drug that's not currently licensed in the country for use in human patients. But other scientists point to the still weak or conflicting evidence base as a strong enough reason why it should not be given an endorsement, at least until a thorough randomised controlled trial is done.

\section{Rise of an unlicensed treatment}

In April 2020, researchers at Monash University in Australia reported that ivermectin inhibits the replication of SARS-CoV-2 in vitro. ${ }^{2}$ By June 2020, it had been added to the treatment guidelines of Bolivia, Guatemala, and Peru, ${ }^{3}$ on the basis of a since retracted preprint by the discredited company Surgisphere and popular demand. ${ }^{4}$ Its use is now widespread, although Peru later withdrew its recommendation, but the Pan-American Health Organisation has issued a warning against using ivermectin to treat covid-19. ${ }^{5}$

In December 2020, Pierre Kory, president of the Frontline Covid-19 Critical Care (FLCCC) Alliance-a group of US doctors looking "to research and develop lifesaving protocols for the prevention and treatment of COVID-19 in all stages of illness" 6 -spearheaded a call for the immediate use of ivermectin, following a meta-review by its expert panel. ${ }^{7}$ In a presentation to the US Senate, Kory was emphatic: "If you take this drug you won't get sick."

Soon after, Andrew Hill, a senior research fellow at Liverpool University doing research on ivermectin for Unitaid, broadcast the findings of his own meta-analysis on YouTube. ${ }^{8}$ Both the video (since removed) and Kory's senate hearing quickly racked up millions of views.
On 6 January 2021, the Frontline Covid-19 Critical Care Alliance and Hill presented their findings to the US National Institutes of Health, which ruled "there are insufficient data to recommend either for or against the use of ivermectin for the treatment of COVID-19. Results from adequately powered, well-designed, and well-conducted clinical trials are needed to provide more specific, evidence-based guidance."9

Advocates argue that there is no time for randomised trials when the death toll continues to rise and vaccines are being distributed only slowly. The argument presented for emergency authorisation is that ivermectin has a long and safe history.

However, this is precisely why large scale platform trials like the WHO's Solidarity trail exist-and ivermectin has never been chosen for evaluation in any of them.

Caroline Wood, spokesperson for the UK's RECOVERY trial, told The BMJ that the UK COVID-19 Therapeutics Advisory Panel-the independent panel of experts that recommends what treatments should be proposed for testing through the various UK platform trials ${ }^{10}$-were unconvinced of the biological rationale for an antiviral effect. "They felt the evidence of a clinically relevant anti-inflammatory effect was weak and that the current clinical evidence and meta-analyses were not sufficiently robust to recommend ivermectin [for further study].”

Smaller randomised control trials are under way or being registered in several countries. A preprint published on 23 February by researchers in Mexico stated: "In non-critical hospitalized patients with COVID-19 pneumonia, neither ivermectin nor hydroxychloroquine decreases the number of in-hospital days, respiratory deterioration, or deaths." 11 And a small double blind, randomised control trial in Colombia done between July and November 2020 and published in March found that the duration of symptoms was not significantly different compared with the placebo for patients with mild covid-19 symptoms given a five day course of ivermectin at 10 times the recommended dose. ${ }^{12}$

Salim Rezaie, an emergency medicine physician at Greater San Antonio Emergency Physicians, has analysed several ivermectin studies on his blog Rebel EM. ${ }^{13}$ His verdict is that the data are still inconclusive.

“We've seen lots of poorly done studies initially with other drugs, only to show no mortality benefit when done in better done randomized clinical trials," he says. "I don't think physicians have a misunderstanding of the science, but they so badly want a treatment option for a terrible disease it seems 
we [doctors] continue to do the same thing over and over again."

\section{Exceptional use}

In South Africa, Hill's viral video coincided with a second wave of cases and deaths. Demand for a drug that's not registered in the country surged among citizens and doctors alike.

Grassroots groups like the Ivermectin Interest Group, comprising doctors, scientists, and pharmacists, and the physician group I Can Make A Difference have assembled online and argued their case on social and mainstream media. They say they support the call for clinical trials but have a right to prescribe a "life saving" drug that will reduce hospitalisation rates in the interim, citing Hill and Kory's analyses as evidence. Doctors and patients share anecdotal evidence through email and WhatsApp. "We know the drug works," says Naseeba Kathrada, a GP and founder of I Can Make A Difference. "Even for those using the veterinary drug, we've had no reports of toxicity."

But ivermectin is not approved for human consumption in South Africa, and while the veterinary formulation is stocked at farmers' cooperatives, amounts are limited (and prices vary-globally, they range from €0.04 to $€_{3.00}\left(€ 0.05\right.$ to $€_{3.50}$; \$0.06 to \$4.20) per tablet).

Even if a doctor could get hold of the drug, its use in patients to treat covid-19 would be legal only if specific approval for that patient-under "compassionate" grounds-is granted by the South African Health Products Regulatory Authority (SAHPRA). That exception was only granted in January, after the Ivermectin Interest Group filed a high court motion against SAHPRA. (I Can Make A Difference has also filed its own court motion against SAHPRA to widen approval and availability of ivermectin. A judge will hear the case at the end of March.)

A SAHPRA spokesperson told The BMJ, "At present, there are no approved treatments for COVID-19 infections."

\section{Concerns}

Regardless, doctors are somehow still administering ivermectin off label. "Nobody will say where they got it from," says Kathrada, "but in some cases, patients are taking the drug to their doctors and asking for advice."

Desperation has led to a runaway movement. Buoyed by the media and social media visibility of local doctors advocating for ivermectin use, a lobby group, South Africa Has A Right To Ivermectin, formed on Facebook on 2 January 2021. Its 72 ooo members, including some who claim to be healthcare workers, share information about where to obtain the drug-often smuggled into the country and available on the black market at vastly inflated prices-at what dose, topically or orally, and how to use the veterinary formulation. The group has embarked on an awareness campaign for "the people's medicine," physically distributing pamphlets on the benefits of ivermectin at public spaces throughout the country.

Kathrada, unwittingly hailed by the movement as a symbolic figure, is concerned about the group's anti-vaccination agenda. It believes ivermectin is sufficient as a prophylactic, and the messaging often comes mixed in with conspiracy theories.

On 5 March, the US Food and Drug Administration issued a warning on the use of veterinary ivermectin. "The FDA has received multiple reports of patients who have required medical support and been hospitalized after self-medicating with ivermectin intended for horses," it said in a statement. ${ }^{14}$

Philipp Rosoff, professor emeritus of paediatrics and medicine at Duke University Medical Centre and School of Medicine in the US, says doctors "are just as susceptible to the availability heuristic as anyone else and use the experience of their ' $n$ of 1 ' one-off 'experiments' on a single patient to signify more importance than what their observations might warrant."

For him, advocating for "the supposed benefits of an unproven therapeutic when the sole justification is the desperation of the situation and the relative "safety" of the drug is inherently dishonest and hence ethically problematic."

\section{Box 1: Other contested treatments}

\section{Colchicine}

Since November 2020, the UK RECOVERY trial has included a randomised comparison of colchicine, an anti-inflammatory drug that is commonly used to treat gout, versus standard of care alone. To date there has been no convincing evidence of the effect of the drug on clinical outcomes in patients admitted to hospital with covid-19.

\section{Vitamin D}

Much like ivermectin and hydroxychloroquine, advocates for the use of vitamin D formed an alliance. The Vitamin D for All Coalition is a volunteer group of more than 110 scientists, doctors, and leading authorities around the world calling for an increase in vitamin D use to combat covid-19. However, a panel made up of the National Institute for Health and Care Excellence, Public Health England, and the Scientific Advisory Committee on Nutrition found insufficient evidence to recommend it for treating or preventing the disease. ${ }^{15}$

\section{Convalescent plasma}

Early findings from the international REMAP-CAP trial found no benefit for patients who are critically ill or in intensive care. ${ }^{16}$ The RECOVERY trial also saw "no convincing evidence of the effect of convalescent plasma on clinical outcomes in patients admitted to hospital with COVID-19."17

Competing interests: I have read and understood BMJ policy on declaration of interests and have no relevant interests to declare.

Provenance and peer review: Commissioned; not externally peer reviewed.

Crump A, Ōmura S. Ivermectin, 'wonder drug' from Japan: the human use perspective. Proc Jpn Acad Ser B Phys Biol Sci2011;87:13-28. doi: 10.2183/pjab.87.13. pmid: 21321478

2 Caly L, Druce JD, Catton MG, Jans DA, Wagstaff KM. The FDA-approved drug ivermectin inhibits the replication of SARS-CoV-2 in vitro. Antiviral Res 2020;178:104787.

doi: 10.1016/j.antiviral.2020.104787. pmid: 32251768

3 Mega ER. Latin America's embrace of unproven COVID treatment hinders drug trials. Nature 2020;20. https://www.nature.com/articles/d41586-020-02958-2.

4 Patel AN, Desai SS, Grainger DW, Mehra MR. Ivermectin in COVID-19 related critical illness [retracted]. https://www.isglobal.org/documents/10179/6022921/Patel+et+al.+2020+version+1.pdf/fab19388-dc3e-4593-a075-db96f4536e9d.

5 Offord C. Surgisphere sows confusion about another unproven COVID-19 drug. Scientist. 2020 https://www.the-scientist.com/news-opinion/surgisphere-sows-confusion-about-another-unproven-covid19-drug-67635.

6 Frontline Covid-19 Critical Care Alliance. About us. https://covid19criticalcare.com/about.

7 Kory P, Meduri GU, Iglesias J, et al. Review of the emerging evidence supporting the use of ivermectin in the prophylaxis and treatment of COVID-19-updated Jan 12, FLCCC.

https://covid19criticalcare.com/wp-content/uploads/2020/11/FLCCC-Ivermectin-in-the-prophylaxis-and-treatment-of-COVID-19.pdf.

8 Hill A, Abdulamir A, Ahmed S, et al. Meta-analysis of randomized trials of ivermectin to treat SARS-CoV-2 infection. Research Square. 9 January 2021, Preprint (version 1). https://www.researchsquare.com/article/rs-148845/v1.

9 National Institutes of Health. Ivermectin: COVID-19 treatment guidelines. https://www.covid19treatmentguidelines.nih.gov/antiviral-therapy/ivermectin.

10 GOV.UK. UK COVID-19 Therapeutics Advisory Panel (UK-CTAP). Guidance: making a proposal for covid 19 therapeutics clinical trials. https:/www.gov.uk/government/publications/covid-19treatments-making-a-proposal-for-clinical-trials/guidance-making-a-proposal-for-covid-19-therapeutics-clinical-trials\#uk-covid-19-therapeutics-advisory-panel-uk-ctap.

11 Gonzalez JLB, Gamez MG, Enciso EAM, etal. Efficacy and safety of ivermectin and hydroxychloroquine in patients with severe COVID-19. A randomized controlled trial.medRxiv 2021.02.18.21252037; doi: 10.1101/2021.02.18.21252037.

12 López-Medina E, López P, Hurtado IC, etal. Effect of ivermectin on time to resolution of symptoms among adults with mild COVID-19: A randomized clinical trial. JAMA 2021;4 doi: 10.1001/jama.2021.3071. pmid: 33662102 
13 Rezaie S. COVID-19 update: Ivermectin. REBEL EM. Emergency medicine blog 16 Dec 2020. https://rebelem.com/covid-19-update-ivermectin.

14 US Food and Drug Administration. Why you should not use ivermectin to treat or prevent COVID-19.5 March 2021. https://www.fda.gov/consumers/consumer-updates/why-you-shouldnot-use-ivermectin-treat-or-prevent-covid-19.

15 National Institute for Health and Care Excellence. COVID-19 rapid guideline: vitamin D. NICE Guidance NG187. https://www.nice.org.uk/guidance/ng187/chapter/Recommendations.

16 Wise J. Covid-19: Convalescent plasma may cut deaths in patients not on ventilation, study indicates. BMJ2021;372:n130. doi: 10.1136/bmj.n130 pmid: 33446489

17 RECOVERY. RECOVERY trial closes recruitment to convalescent plasma treatment for patients hospitalised with COVID-19. 15 January 2021. https://www.recoverytrial.net/news/statementfrom-the-recovery-trial-chief-investigators-15-january-2021-recovery-trial-closes-recruitment-toconvalescent-plasma-treatment-for-patients-hospitalised-with-covid-19.

This article is made freely available for use in accordance with BMJ's website terms and conditions for the duration of the covid-19 pandemic or until otherwise determined by BMJ. You may use, download and print the article for any lawful, non-commercial purpose (including text and data mining) provided that all copyright notices and trade marks are retained. 